\title{
ENTREVISTA
}

\section{TECNOLOGIA EXPONENCIAL E OS NOVOS DESAFIOS DA SOCIEDADE CONTEMPORÂNEA}

$\mathbf{M}$ arcos Cavalcanti fundou o Centro de Referência em Inteligência Empresarial (CRIE), em 1988, e foi nesse espaço que recebeu Sílvia Borges Corrêa, Veranise Jacubowski Correia Dubeux, Simone Terra e Daniela Jacques para uma entrevista sobre a nova sociedade do conhecimento, que desponta trazendo novos valores e paradigmas. Uma das transformações mais significativas é que a visão cartesiana de um mundo é insuficiente para a sociedade atual lidar com tanta complexidade e diversidade de informação digital em rede. Assim, o Big Data é considerado um reflexo desta nova sociedade, na qual a tecnologia passa a ter um papel central. Cavalcanti pontua que, possivelmente, em um futuro bem próximo, a tecnologia e a internet se transformarão, a partir de uma simbiose, em uma integração com os indivíduos. Dessa forma, a tecnologia vai estar tão presente na vida de cada pessoa que vai se tornar imperceptível. No entanto, Cavalcanti aponta a relevância do ser humano frente à tecnologia, no sentido de que são as pessoas que fazem a diferença, pois sentem e são únicas. A partir dessa perspectiva, alguns conceitos são revistos e paradigmas quebrados, tais como: diversidade, privacidade, criatividade e reputação. Open Data e direito autoral são questões centrais para que a informação não seja controlada por apenas algumas empresas. $O$ risco da internet é que as pessoas se fechem em "bolhas" e em comunidades específicas, trazendo a intolerância. Para Cavalcanti, o mundo está caminhando não para segregar, mas para valorizar o pensamento complexo em uma sociedade que valoriza o conhecimento e a informação. 


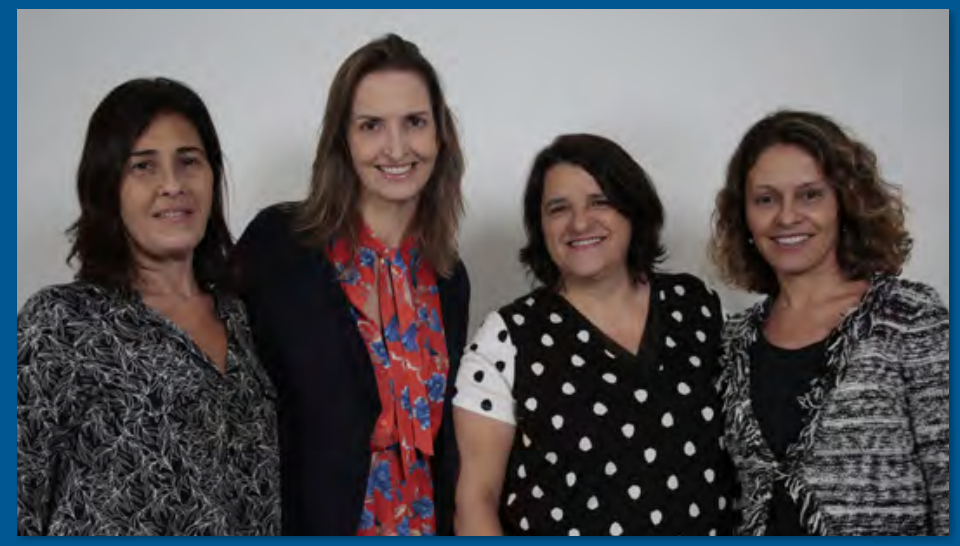

\section{Sílvia Borges Corrêa}

É Doutora em Ciências Sociais pelo Programa de Pósgraduação em Ciências Sociais da Universidade do Estado do Rio de Janeiro (PPCIS/UERJ). Professora Titular do Mestrado Profissional em Gestão da Economia Criativa (MPGEC) da ESPM Rio.sborges@espm.br

\section{Veranise Jacubowski Correia Dubeux}

É Doutora em Engenharia Mecânica pelo Instituto Alberto Luiz Coimbra de Pós-graduação e Pesquisa de Engenharia, da Universidade Federal do Rio de Janeiro - COPPE/UFRJ. Professora Titular do MPGEC - ESPM Rio.vdubeux@espm.br

\section{Simone Terra}

É Mestranda do MPGEC - ESPM Rio. simoneterra@sterra.com.br

\section{Daniela Jacques}

É Mestranda do MPGEC - ESPM Rio.danielajacques@uol.com.br

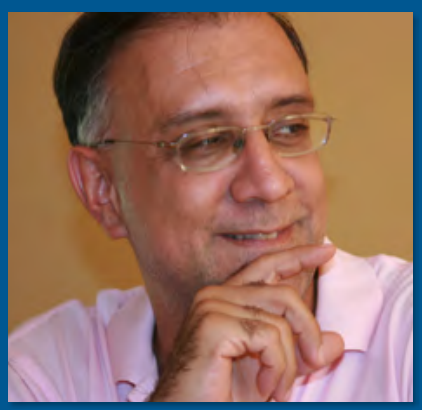

\section{Marcos Cavalcanti}

É Doutor em Informática pela Université de Paris XI, professor da COPPE/UFRJ e coordenador dos cursos de pós-graduação Master on Business and Knowledge Management (MBKM) e Web Intelligence \& Digital Ambience (WIDA).

marcos@crie.ufrj.br 
Entrevistadoras - Você poderia falar um pouco sobre como a sociedade se modificou ao longo do tempo, com a apropriação da tecnologia e o Big Data?

Marcos Cavalcanti - É importante entendermos o contexto. Com minha experiência de 20 anos estudando esses assuntos, penso em que mundo é esse que estamos vivendo. Acho que boa parte dos erros que a gente comete, inclusive com uso da tecnologia, é porque a gente descontextualiza, fica tentando analisar a tecnologia como se ela pudesse existir fora de um contexto, de uma história, de uma trajetória de vida. Então, primeiramente, o que eu faria é dar esse contexto. A gente está vivendo em um mundo que está passando por um processo de revolução, não é uma transformação apenas, pois já estamos com os dois pés em uma nova sociedade, na qual os principais fatores para criar riqueza não são mais terra, capital, mão de obra, energia e matéria-prima, mas sim o conhecimento. É uma sociedade conectada em rede, na qual as tecnologias digitais têm um papel importante. Isso é uma revolução, não é só uma mudança quantitativa, é uma mudança qualitativa. A gente está pensando de forma diferente da que pensávamos no século 20, em todos os sentidos, não só na economia, mas na maneira de se produzir as coisas: antes era a fábrica que produzia os bens e as riquezas da sociedade e, hoje, a principal riqueza tem a ver com o conhecimento; são produtos e materiais intangíveis, como softwares, produtos da indústria cultural, filmes, música, consultoria, sistema financeiro, pagamento de royalties. A fábrica deixou de ser o local principal de se produzir riqueza, e a casa das pessoas passou a ser esse local. Então, é outro mundo, essa revolução em marcha está transformando tudo, inclusive nossa maneira de pensar. A transformação é econômica, cultural e social. Diante disso é que surgiram as tecnologias e o Big Data, que é só um componente nesse contexto, que contribui certamente para aprofundar e acelerar essa transformação, mas, ao mesmo tempo em que ele contribui, é reflexo disso, ele surge dessa necessidade de lidarmos com a complexidade do mundo. Uma das transformações mais significativas é que estamos percebendo que a visão cartesiana de mundo que nos trouxe até aqui é insuficiente para lidar com a complexidade, diversidade de informações. Nós estamos em uma revolução. Não é o fim do mundo, como pensam muitas pessoas pessimistas, desanimadas. Eu penso o contrário, sou otimista, penso que não estamos vivendo o fim do mundo, mas o fim de um determinado mundo e o início de outro mundo. Isso não é uma coisa linear, a fronteira entre o velho mundo e o novo mundo não é uma data. Estamos vivendo esse momento de transição, mas me parece muito evidente que já estamos na sociedade do conhecimento, digital e em rede. O que está ficando para trás é a sociedade industrial e burguesa tradicional. Temos que saber diferenciar o que é joio e o que é trigo, o que é portador de futuro e o que é herança que a gente deveria deixar no passado. 
Entrevistadoras - Você consegue olhar e interpretar quais são os próximos desafios mediante esta nova sociedade que emerge a partir desse conhecimento?

Marcos Cavalcanti - Vou começar falando do Big Data e depois dos desafios. O Big Data, expressão que se tornou mais popular, tem a ver com um negócio chamado Ciência das Redes, que é uma ciência que estuda esses fenômenos das redes sociais e da digitalização da informação. Então, falando do Big Data, diria que tem cinco características: volume de dados, variedade/diversidade dos dados, veracidade, velocidade e privacidade.

Entrevistadoras - Você acredita que o significado da privacidade mudou em nossa sociedade?

Marcos Cavalcanti - Já mudou. Muita gente vê isso com preocupação e com razão, pois existem limites para você invadir a privacidade de uma pessoa. Você não pode sair divulgando uma imagem de uma pessoa em casa, ou revelar o que ela fez na casa dela. Você não deveria poder compartilhar sem o consentimento dessa pessoa. Há limites para a privacidade e teremos que brigar por isso. Mas o conselho que eu daria é o seguinte: seja você mesmo o tempo todo. Vejo um lado positivo nessa relativa invasão da privacidade, que é a diminuição da hipocrisia, pois você desmarcara a pessoa.

Entrevistadoras - E, mediante esse cenário, a reputação vira uma moeda de valor?

Marcos Cavalcanti - Sim, aliás, já é. Uma das grandes questões hoje é a confiança, a reputação de alguém. Como tomamos decisões para fazer qualquer coisa? Ouvimos várias opiniões, aí está o papel da rede. A opinião de alguém que você sabe que entende daquilo é muito relevante. Às vezes, a pessoa tem a reputação de saber daquele assunto, então você busca aquela pessoa. Mas se você descobre que a pessoa ganhou dinheiro de uma marca para falar bem dela, a reputação dela cai por terra, e você deixa de valorizar a opinião dela.

Entrevistadoras - O que você consegue enxergar, como pesquisador, professor e também consumidor, sobre os próximos desafios que vamos ter nesta sociedade do conhecimento?

Marcos Cavallcanti - Alguns, mas vou dizer dois que acho que são grandes desafios. O primeiro é o uso da tecnologia, que vai estar cada vez mais presente em nossas vidas. O presidente do Google falou uma frase há dois anos que causou polêmica: "A internet vai acabar." O que ele estava querendo dizer é que ela estará tão presente em nossa vida que nem vamos perceber que ela existe. Tenho certeza que daqui a pouco tempo isso vai deixar de 
ser uma questão. A gente estará falando aqui e não precisará nem segurar o celular. A estrutura hoje de uma pessoa é cabeça, membros, tronco e celular. Ela não consegue mais viver sem o celular, isso vai desaparecer; esse aparelho vai desaparecer. Nós vamos estar conectados ao celular por chips, óculos, pulseiras, e vou falar com as pessoas, consultar o Google e aparecerá a imagem na minha cabeça sem eu precisar ver uma tela, sem precisar ter um aparelho físico na minha mão. Acredito que a tecnologia e a internet vão desaparecer, pois elas estarão em simbiose conosco. Um dos grandes desafios é pensar como fica o ser humano nisso. Muita gente acha que a tecnologia vai dominar o ser humano, mas eu não acredito. Acho que os humanos controlarão as máquinas, e não o contrário - mas posso estar errado -, porque acho que o desafio é o sentimento; o computador não ama, não é amigo, não chora, não sente dor. A tecnologia iguala todo mundo, mas as pessoas fazem a diferença, e isso é real. A neurociência já mostrou que boa parte do conhecimento humano não é fruto das informações, mas das emoções, e isso nos torna únicos. A tecnologia nos faz parecer iguais, mas por que somos tão diferentes ainda? Acho que somos cada vez mais diferentes. Achava-se, há 20 anos, que a globalização iria homogeneizar tudo, todo mundo iria comer McDonald's, vestir a mesma roupa, e não foi isso que aconteceu, a diversidade aumentou. Diversidade na alimentação, na maneira de se vestir e de se comportar, na estética... A diversidade aumentou, e, nesse sentido, um dos desafios é como faremos a humanidade continuar percebendo que as emoções que sentimos fazem a diferença. Acredito que a ciência vai avançar nesse sentido. O que hoje em dia é uma percepção de vários médicos, por exemplo, de que a fé e a vontade de viver interferem fisicamente na evolução do tratamento de uma doença como o câncer, acredito que vamos chegar à conclusão que existem coisas imateriais que nos transformam fisicamente. Tem um cientista brasileiro, o Miguel Nicolelis, que, na abertura da Copa do Mundo do Brasil, fez um garoto tetraplégico dar um chute em uma bola, com uma perna mecânica, mandando sinais do cérebro dele. Ele descobriu um sensor que capta sinais que o cérebro emite e transformou isso em ação. A pessoa pensa que quer chutar a bola, e o sensor capta essa ordem e transmite para uma máquina que chuta a bola. $\mathrm{O}$ sensor estava lendo o pensamento. Isso não é ficção científica, aconteceu na abertura da Copa. A empresa GE - General Electric - vai dizer o dia, a hora e os minutos em que a geladeira da sua casa vai parar de funcionar. $E$ isso não vai ser bruxaria, vai ser porque vai cruzar um monte de dados que está captando hoje em dia e vai ser capaz de dizer que em tal dia a geladeira vai parar. Tem um professor da COPPE, Nelson Ebecken, especialista em Big Data, que me contou que a Petrobras hoje em dia tem sensores embaixo d'água perto das plataformas, para analisar continuamente a qualidade da água, para poder detectar um vazamento de óleo rapidamente. Aí eu brinquei: "Esses sensores são caros?". Ele disse: "Não, cada vez mais baratos". Então, eu completei: "Se eu botar esse sensor na minha privada, eu vou poder ter um exame de fezes e de urina imediato, várias vezes ao longo do dia". E se eu botasse sensores nas privadas de todas as casas do Brasil e captasse esses 
dados durante cinco anos, eu teria um monte de dados, uma variedade de informações sobre que componentes químicos fazem parte das fezes e da urina do Marcos, do João e da Maria... durante cinco anos, várias vezes ao dia. E tenho certeza que vamos descobrir padrões do tipo "toda pessoa que teve câncer, durante cinco anos, tomou cerveja e comeu pitaia três vezes por semana". Posso até não descobrir como curar o câncer, mas vou descobrir correlações que hoje não consigo nem imaginar, pois não tenho dados, não tenho sensores adequados para coletar esses dados. Na hora em que a gente descobrir que nosso cérebro emite de fato ondas que podem ser captadas por um sensor e ler o pensamento de alguém, não vai parar por aí, vamos descobrir novas coisas, o que pode ser um perigo. As relações afetivas vão mudar profundamente.

Entrevistadoras - Com o possível acesso a informações pessoais, como fica a nossa privacidade?

Marcos Cavallcanti - Foi para outro limite. Vai acabar a privacidade se eu ler o pensamento do outro? Acho que não, vai ter outra coisa que você vai poder esconder lá dentro, no fundo da sua alma, e que ninguém vai penetrar ali. Eu acredito que vamos avançar, sou um otimista. Um dos desafios é não perder a humanidade, continuar acreditando na humanidade. E o outro desafio é a tolerância, é aprender a conviver com a diversidade. Tem uma frase do Oscar Wilde que eu adoro: "Seja você mesmo; todos os outros personagens já têm dono". Paradoxalmente, o que o fim da privacidade, a maior diversidade e o maior acesso à informação estão trazendo é a possibilidade de cada um ser o que realmente é.

Entrevistadoras - Aproveitando essa sua linha de pensamento, algumas pessoas acham que a internet traz também a possibilidade de você construir vários personagens e aumentar a realidade. Você cria paixões, personagens, momentos felizes, situações que você não vive. Inclusive, tem um site que faz uma brincadeira de pessoas que postam fotos que não são a realidade. Tem uma menina que parece que está na praia, mas está no meio de uma obra. Mas quando se olha só o recorte da foto, ela está em uma praia paradisíaca. Então, são informações contraditórias e, ao mesmo tempo, complementares. Você pode falar um pouco sobre isso?

Marcos Cavallcanti - Você falou um ponto muito importante. Imagina só: eu uso óculos, e estamos aqui nessa sala horrorosa no Fundão. E se meus óculos me fizessem ver que estávamos em uma praia? Olha o desespero disso, porque eu poderia morar em um cubículo de dois metros quadrados e a realidade aumentada e virtual iria me fazer imaginar em uma janela para um oceano lindo, uma montanha maravilhosa, e eu não teria a sensação de viver em um cubículo, eu ia estar me iludindo. A pessoa estará vivendo lite- 
ralmente isso, um mundo virtual, que não é real, embora você tenha todas as sensações. Então, isso é um risco.

Entrevistadoras - Você considera possível, por meio da tecnologia, adquirir e ser aceitável você ter várias personalidades ou identidades?

Marcos Cavalcanti - A tecnologia vai nos permitir fazer várias barbaridades, como a tecnologia nuclear nos permitiu fazer a bomba atômica e matar milhares de pessoas. A mesma tecnologia que permite desenvolver alimentos saudáveis e salvar pessoas da fome, ou ter uma intervenção cirúrgica via raio laser e salvar várias pessoas. Então, o uso que o ser humano vai fazer da tecnologia envolve não perder o espírito crítico, não ficar deslumbrado com a tecnologia, com a internet, com o Google. Uma das ameaças que a gente tem nesse mundo de Big Data é que quem manda no mundo hoje não são mais as grandes empresas de petróleo ou os banqueiros, as pessoas mais ricas não são os donos do dinheiro, são aqueles que controlam a informação. O Google e o Facebook estão disputando esse controle de informações. O que eu posto no Facebook, o Google não acha; se eu botar no Facebook, tudo que eu escrevi não aparece nada no Google; um bloqueia o outro. E eles estão atrás de obter informação. Eu acho que o Big Brother é uma ameaça real, alguém que controla todas as informações e sabe tudo. Nós temos que criar antídotos para isso. Nós temos que estar alertas, destruir o poder do Google e do Facebook, e não dar a ninguém esse poder de controlar todas as informações do mundo, pois, quem fizer isso, vai controlar o mundo. Isso é um risco, uma ameaça, é o desafio do século 21 . O antídoto para isso é eu, legalmente, ter o direito a tudo que posto no Facebook. O Facebook tem que me dar tudo que sabe sobre mim, ele é obrigado. Ele pode fazer o que ele quiser com as informações que eu coloco lá, mas ele tem que me dar o que é meu. Temos que desenvolver um aplicativo e uma campanha que diga: 'Facebook, eu autorizo que esse algoritmo libere para todo mundo tudo que você sabe sobre mim'. Na hora em que o Facebook não for o único dono, e todo mundo souber tudo que eu boto no Facebook, o valor de mercado do Facebook despenca.

Entrevistadoras - Isso seria uma grande revolução de direito autoral e de imagem?

Marcos Cavalcanti - Isso é totalmente relevante. Vamos mudar a lei de patente, de direito autoral. Claro que é importante, pela questão da reputação, saber determinada frase do Fernando Pessoa. Mas eu assisti a uma palestra do João Paulo Cuenca, que é um escritor da nova geração, e ele falou que escreveu um livro inteiro com frases que foi pegando de outras pessoas, e nada disso foi plágio, pois plágio é só quando você repete um trecho. 
Entrevistadoras - Isso é muito interessante, inclusive para quem está na academia. Você tem todo aquele formato e as normas da Associação Brasileira de Normas Técnicas (ABNT) que precisam ser seguidas. Quando ele escreve um livro assim, isso não seria plágio do ponto de vista acadêmico?

Marcos Cavalcanti - Tem razão. E eu posso ter um algoritmo e fazer uma tese juntando três palavras de algum autor.

Entrevistadoras - Mas para o mercado é aceitável?

Marcos Cavallcanti - Não sei se é aceitável, estou dizendo que isso é viável, e o João Paulo Cuenca fez.

Entrevistadoras - Isso quebra paradigmas.

Marcos Cavallcanti - Muda tudo. Que grande descoberta foi realmente da cabeça daquele cara? Ele não se inspirou em alguma coisa que ele viu, às vezes, outro assunto? Certamente, é assim que funciona a criatividade. Ninguém inventou uma coisa completamente do zero.

Entrevistadoras - Estamos em 2017 e tantas coisas já foram feitas, criadas e produzidas. Como ser original?

Marcos Cavallcanti - Foi o Neruda que escreveu isso? Veio da cabeça dele? Aí alguém me mostra um grego de 400 anos antes. Quem garante que o Neruda não leu um negócio parecido? Você está preocupado com quem disse, ou com o que foi dito? Para mim, o relevante é o conteúdo. Claro que quem diz é um componente também. Mas, na verdade, o que é mais importante é o conteúdo.

Entrevistadoras - Isso provoca uma reflexão, pois é um assunto contemporâneo, que vem junto com a questão da tecnologia, que nos faz rever muitos conceitos. Como fica essa questão da autoria, da assinatura?

Marcos Cavallcanti - Ouvindo você falar, me veio uma palavra à cabeça chamada 'alma'. Vamos sair do universo da arte, da literatura e pensar em um processo de seleção dentro da empresa. Geralmente, as pessoas ficam querendo ver currículo, a experiência, se ele sabe falar inglês etc. Aí no currículo a pessoa tem os requisitos do cargo, tem um diploma de Stanford. A empresa contrata o sujeito, mas às vezes ninguém nem fala com ele. Aí dá errado, porque se exige objetividade no processo seletivo. Então, o que eu quero dizer com isso: Cartola e Chico Buarque, por que eles são gênios? Porque são verdadeiros no que estão dizendo, e você percebe isso. Eles falam em uma dimensão que eu acredito que seja aquilo que faz alguém ter uma assinatura: a 'alma'; ser verdadeiro. 
Entrevistadoras - Eu considero interessante você trazer a questão dos dados e da tecnologia versus a questão da alma e da importância da sensibilidade.

Marcos Cavalcanti - No meu ponto de vista, não dá para ser separado. Para qualquer atividade que for suficiente cruzar dados para chegar a uma conclusão, o computador vai fazer melhor que eu, porque ele vai cruzar muito mais dados. Tem um estudo muito interessante de um americano sobre a capacidade de o ser humano tomar decisão. Em Nova York, tinha uma loja com mais de 50 tipos de azeite, que ele analisou e ficou surpreso, pois imaginava que os clientes daquela loja seriam os mais satisfeitos do mundo, pois, entre 50 tipos, eles iriam encontrar um que os interessasse. Mas descobriu que os clientes saíam extremamente insatisfeitos, porque saíam da loja comprando um azeite, e sempre achavam que poderiam ter comprado outro, não conseguiam usufruir daquele que foi comprado. Esse pesquisador chegou à conclusão de que o ser humano só consegue decidir entre cinco opções. Se der mais de dez opções, a pessoa já vai ficar confusa. A máquina vai conseguir tomar decisões muito melhores analisando 20 mil possibilidades do que eu. Mas vamos ter algo que a máquina nunca terá, e que eu chamei de 'alma', na falta de um nome melhor. O Karl Polanyi chama de 'conhecimento tácito'. Esse 'conhecimento tácito', que eu chamei de 'alma', é essa percepção que tem a ver com experiência de vida da pessoa.

Entrevistadoras - Esse conhecimento que temos por meio do cruzamento desses grandes dados pode ser considerado sempre relativo, pois depende mais do olhar humano e da forma que os dados são interpretados?

Marcos Cavalcanti - Eu acredito nisso. Por mais que você tenha algoritmos fazendo análise desses dados, o que é um avanço inevitável, eu acredito que vai ter sempre essa coisa do humano ali.

Entrevistadoras - Até para não ser uma interpretação errada, pois a tecnologia pode errar?

Marcos Cavalcanti - Claro que pode. A tecnologia vai fazer o que você mandá-la fazer. Ela erra muito menos que a gente, pois ela faz o que eu a mandei fazer, o comando é do homem.

Entrevistadoras - Eu vou trazer minha visão de alguém que faz pesquisa etnográfica, porque existem informações que você não consegue identificar apenas cruzando os dados. Por exemplo, a interpretação do tom que a palavra é dita: um "não" exclamação é diferente de um "não" interrogação.

Marcos Cavalcanti - O que você está analisando é o conhecimento explícito, é o que já está no papel. Uma das coisas que fazemos no sistema das redes, e Albert-László Barabási é o iniciador disso. Ele diz 'a topologia da 
rede determina o que você é capaz de fazer e o que você não é capaz de fazer'. Uma criança de dois meses de idade não é capaz de andar. A topologia da rede dela, a composição óssea, os neurônios não permitem que um bebê de dois meses de idade ande; não tem jeito. Já o cavalo não é assim, ele nasce e já fica em pé, e nunca mais deita. Se ele deita, está doente e vai morrer. A topologia da rede de um cavalo faz com que ele saia da barriga da mãe andando. O que é topologia? A estrutura da rede: quem está conectado com quem, os nós, os links, as conexões entre pessoas, mas é também a intensidade dessa conexão, quantas vezes nos falamos por dia, o sentido dessa direção.

Entrevistadoras - Você poderia falar um pouco mais sobre a topologia das redes?

Marcos Cavallcanti - Eu diria para você com base no que estudei sobre conhecimento, pensamento humano, e, citando novamente Karl Polany, 'nós pensamos o que pensamos porque interagimos com determinadas pessoas e ideias ao longo da vida'. No Facebook existe esse problema da bolha. Tem gente que está envolvido em algum assunto e só conversa com quem está envolvido nisso.

Entrevistadoras - Quais são os principais desafios?

Marcos Cavalcanti - Um desafio é não ficar idolatrando ideologia. O outro desafio é não deixar o negócio do Google e do Facebook acontecer através do Open Data. O terceiro desafio é esse, não se deixar ficar na bolha. É preciso manter a diversidade, e isso tem a ver com tolerância. O que precisa ter na escola? Para mim, se a escola tivesse que ensinar uma coisa, não seria só tolerância, mas também valorizar a diversidade, o que é mais do que aceitar. Aprende-se português e matemática, mas a escola tem que ser o espaço da valorização da diversidade, você tem que aprender que isso é rico. Não é uma opção apenas filosófica. Darcy Ribeiro dizia que a grande oportunidade do Brasil é essa diversidade. O Brasil tinha um papel no mundo que é esse, o de valorizar a diversidade. Agora estamos conversando, estamos trocando ideias e bactérias. Eu vou sair com bactérias novas e vocês também. O que acontece é que o sistema imunológico diz: "opa, bactéria nova!", mas não faz nada. Se ela entrar no seu organismo e não causar nenhuma comoção, beleza! É mais uma bactéria nova, você vai se tornar mais diverso, um corpo mais robusto. Quanto maior a diversidade, maior a robustez, a medicina já sabe isso. Darcy Ribeiro falava isso, que o brasileiro é feito de índio, negro e branco. A bossa-nova, o chorinho, são misturas de vários ritmos. Esse é outro desafio. Como vamos valorizar a diversidade. E voltando ao Big Data, é um elemento que joga água nesse moinho, ao permitir que valorizemos a diversidade. O mundo está caminhando não para segregar, não para valorizar o pensamento cartesiano, mas sim para valorizar o pensamento complexo. 